\title{
Immediate maternal complications associated with thrombocytopenia among women delivering at a tertiary hospital in Southwestern Uganda
}

\author{
David Ruiru', Emmanuel Nzabandora' ${ }^{1}$, Robinson Ssebuufu², Simon Byonanuwe ${ }^{1 *}$
}

\begin{abstract}
${ }^{1}$ Department of Obstetrics and Gynecology, ${ }^{2}$ Department of Surgery, Kampala International University Western Campus, Uganda
\end{abstract}

Received: 14 November 2020

Revised: 18 December 2020

Accepted: 29 December 2020

*Correspondence:

Dr. Simon Byonanuwe,

E-mail: byonsimon@gmail.com

Copyright: (c) the author(s), publisher and licensee Medip Academy. This is an open-access article distributed under the terms of the Creative Commons Attribution Non-Commercial License, which permits unrestricted non-commercial use, distribution, and reproduction in any medium, provided the original work is properly cited.

\section{ABSTRACT}

Background: Thrombocytopenia is a serious threat both to the mother and the fetus world over. We established the prevalence and associated immediate maternal complications of thrombocytopenia among women delivering at Kampala International University Teaching Hospital (KIUTH) so as to help us draw a platform for provision of appropriate interventions.

Methods: A prospective cross-sectional study involving 386 women was conducted in the months of May 2019 to August 2019. Questionnaires and laboratory result forms were used to obtain the data. Data analyses were conducted using STATA version 14.2.

Results: The prevalence of thrombocytopenia was $15.8 \%$. Significant immediate maternal outcomes were placenta abruption which was higher among women with thrombocytopenia $(44.3 \%)$ than those with no thrombocytopenia $(2.2 \% ; \mathrm{p}<0.001)$ and postpartum haemorrhage which was higher among those with thrombocytopenia $(45.9 \%)$ than those with no thrombocytopenia $(6.8 \% ; \mathrm{p}<0.001)$.

Conclusions: Thrombocytopenia is a serious obstetric issue worth paying extra attention at this facility.

Keywords: Haematological abnormality in pregnancy, Immediate maternal outcomes, Thrombocytopenia

\section{INTRODUCTION}

Thrombocytopenia can be a serious challenge during pregnancy both to the mother, her unborn baby and attending obstetrician. It may occur as a physiological phenomenon or may be due to diverse pathological processes and may range from mild to severe state and may have high maternal and fetal mortality. ${ }^{1,2}$ Thrombocytopenia causes approximately $10 \%$ cases of postpartum haemorrhage in developing countries with a maternal mortality of about $5.3 \% .^{3}$ In Uganda, one of the commonest haematological pathology for pregnant women admission in intensive care unit is undiagnosed thrombocytopenia which is noted to be predictive of maternal mortality. ${ }^{4}$ Studies have shown that placenta abruption is more prevalent and more severe among women with thrombocytopenia than in those without thrombocytopenia. ${ }^{5,6}$

At Kampala International University Teaching hospital, although no published literature exists, observation has shown that undiagnosed thrombocytopenia has contributed to several admissions in the hospital's Intensive Care Unit and has been implicated in different cases of maternal deaths on ward. Whereas all pregnant women attending antenatal care at this hospital undergo a routine complete blood count test on their first visit, there is no follow up on haematological studies except for haemoglobin levels. Consequently, we are not able to diagnose thrombocytopenia in pregnancy until 
complications such as postpartum haemorrhage, preterm labour and delivery, and placenta abruption ensue. The current study therefore aimed to identify and document the immediate maternal complications associated with thrombocytopenia among women delivering at KIUTH so as to help us draw a platform for provision of appropriate interventions.

\section{METHODS}

This was a prospective cross-sectional study conducted at KIUTH from May 2019 to August 2019. The study was conducted in Maternity ward which has a bed capacity of 85 and conducts approximately 200 deliveries per month. All women admitted on maternity ward in labour during the study period were enrolled for the study. Data was collected using an investigator administered questionnaire and laboratory report forms for the complete blood count. Mothers were followed up for 24 hours so as to ascertain the immediate maternal complications.

Immediate maternal complications included events during labour (particularly for placenta abruption) as well as events in the first 24 hours after delivery which included postpartum hemorrhage and haematoma at episiotomy site or caesarean section incision site. Sample size was determined using Keish and Leslie formula (1965) where an estimated prevalence of 50\% was used at $95 \%$ confidence interval and a maximum accepted error of $5 \%$ giving a minimum sample size of 386 .

The prevalence of thrombocytopenia was summarized and presented as frequency and percentage. The proportion of mothers with the different immediate maternal complications was summarized as frequencies and percentages and presented in a table. All statistical analyses were carried out in STATA version 14.2.

\section{RESULTS}

Majority of the study participants were Banyankore 345 $(89.38 \%)$, married $376(97.4 \%)$ and practiced peasantry farming $182(47.15 \%)$, with a mean age of 28.2 (Table 1 ).

Of the 386 women enrolled in the study, 61 (15.8\%) had thrombocytopenia. The proportion of the study participants with placentae abruption was higher among women with thrombocytopenia $(44.3 \%)$ as compared to those that had no thrombocytopenia (2.2\%); this was statistically significant; $p<0.001$. The proportion of the study participants who had postpartum haemorrhage was higher among the women with thrombocytopenia $45.9 \%$ compared to those that had normal platelets levels $6.8 \%$; this was statistically significant with $\mathrm{p}<0.001$. There was no statistical significance among women who had haematoma at episiotomy site, $\mathrm{p}=0.0499$ and haematoma at incision site, $\mathrm{p}=0.291$ (Table 2).
Table 1: Socio-demographic characteristics of the study participants $(\mathrm{N}=386)$.

\begin{tabular}{|ll|}
\hline Variables & Frequency $(\%)$ \\
\hline Mean age in years (SD) & $28.2(7.3)$ \\
\hline Age (in years) & \\
\hline $15-17$ & $27(6.99)$ \\
\hline $18-24$ & $113(29.27)$ \\
\hline $25-34$ & $143(37.05)$ \\
\hline $35-49$ & $103(26.08)$ \\
\hline Tribe & \\
\hline Munyankore & $345(89.38)$ \\
\hline Muganda & $22(5)$ \\
\hline Mukiga & $12(3.11)$ \\
\hline Others & $7(1.81)$ \\
\hline Occupation & \\
\hline House wives & $143(37.05)$ \\
\hline Peasant farmers & $182(47.15)$ \\
\hline Business women & $45(11.6)$ \\
\hline Skilled workers & $16(4.15)$ \\
\hline Marital status & \\
\hline Married & $376(97.4)$ \\
\hline Not married & $10(2.5)$ \\
\hline
\end{tabular}

Table 2: Relationship between immediate maternal complications and thrombocytopenia among women delivering at KIUTH.

\begin{tabular}{|llll|}
\hline $\begin{array}{l}\text { Immediate } \\
\text { complication }\end{array}$ & No & Yes & P value \\
\hline $\begin{array}{l}\text { Abruption } \\
\text { placenta }\end{array}$ & $7(2.2)$ & $27(44.3)$ & $<0.001$ \\
\hline PPH & $22(6.8)$ & $28(45.9)$ & $<0.001$ \\
\hline $\begin{array}{l}\text { Haematoma at } \\
\text { episiotomy site }\end{array}$ & $3(0.92)$ & $1(1.64)$ & 0.499 \\
\hline $\begin{array}{l}\text { Haematoma at } \\
\text { incision site }\end{array}$ & $1(0.31)$ & $1(1.64)$ & 0.299 \\
\hline
\end{tabular}

\section{DISCUSSION}

The prevalence of thrombocytopenia among women delivering at Kampala International University Teaching Hospital was $15.8 \%$. This was relatively similar to prior study findings such as one by Olayemi and Akuffo in Ghana where it was noted to be $15.3 \% .^{7}$ Our prevalence was however higher than the global prevalence of $10 \%$ and the one reported by Asrie et al in Ethiopia (8.8\%), Yazdan et al in Iran (5.2\%), as well as that by Nisha et al $(8.8 \%)$ and Vishwekar et al $(8.78 \%)$ both in India. ${ }^{3,8-14}$ This was probably attributed to by the differences in the study settings, for example the good antenatal care facilities and better follow up protocols of all pregnant women allows timely detection and treatment of most medical disorders that would otherwise contribute to thrombocytopenia in pregnancy. This may probably explain the low prevalence in some of these settings. 
Regarding the immediate maternal complications associated with thrombocytopenia, although previous research by Puri et al documented no any maternal complication (except for incision site oozing) associated with severe thrombocytopenia, the present study noted that the proportion of the study participants who had postpartum haemorrhage was higher among women with thrombocytopenia $(45.9 \%)$ compared with those that had normal platelets levels; this was statistically significant with $\mathrm{p}<0.001 .{ }^{9}$ Earlier study reports by Nisha et al, Wang et al, Fakhrolmolouk et al and Sedigheh et al had all reported similar findings. ${ }^{3,15-17}$ Moreover, an earlier study by Parnas et al in Israel had reported a large number of women who received blood in the thrombocytopenic group versus the non-thrombocytopenic group. ${ }^{6}$ And specifically in their study, platelet transfusions for major bleeding were quite more under the thrombocytopenic group compared with the non-thrombocytopenic group. Whereas we could not attribute all the noted postpartum haemorrhage to the thrombocytopenia alone, this finding stresses the need for close maternal surveillance during labour and after delivery for timely detection of such devastating complications.

According to Jodkowska et al, although women with severe thrombocytopenia are able to carry the pregnancy to term, it has been noted that at birth the placenta is separated in fast blood flow through maternal vessels limited due to uterine contractions, and smooth, spontaneous coagulation in the maternal vessels. ${ }^{18}$ It has therefore been documented that compared with pregnant women with normal platelet counts, pregnant women with thrombocytopenia are associated with a higher rate of preterm birth and premature detachment of the placenta. ${ }^{18}$ Similar reports by Vishwekar et al and Vijay et al have been noted. Gašparović et al had reported a case of postpartum haemorrhage in the patient with severe gestational thrombocytopenia and another case of placental abruption in the patient with moderate gestational thrombocytopenia. ${ }^{14,19,20}$ Our findings were indeed no different despite the fact that we could not rule out any possible confounders to this variable. We observed that the proportion of study participants who had placenta abruption was significantly higher among women with thrombocytopenia $(44.3 \%)$ as compared to those that had no thrombocytopenia (2.2\%), $\mathrm{p}<0.001$. Further research with all major confounders for placenta abruption in women with thrombocytopenia well checked is desired to further strengthen this observation.

\section{Limitation}

We did not include more details of the baseline population and number of women with thrombocytopenia who were not recruited, and this could have impacted on our overall prevalence. Future studies in this area targeting such aspects are desired.

\section{CONCLUSION}

Thrombocytopenia is a serious obstetric issue among women delivering at KIUTH and is therefore worth paying extra attention.

\section{ACKNOWLEDGMENTS}

We acknowledge and appreciate all the participants who consented to participate in the study.

Funding: No funding sources

Conflict of interest: None declared

Ethical approval: The study was approved by the Institutional Ethics Committee

\section{REFERENCES}

1. Asif N, Hassan K. Thrombocytopenia in pregnancy. Hematol Transfus Int J. 2017;5(5):1-4.

2. Perepu U, Rosenstein L. Maternal thrombocytopenia in pregnancy. Proc Obstet Gynecol. 2013;3(1):1-15.

3. Nisha S, Amita D, Uma S, Tripathi AK, Pushplata S. Prevalence and characterization of thrombocytopenia in pregnancy in Indian Women. Indian J Hematol Blood Transfus. 2012;28(2):77-81.

4. Nakimuli A, Nakubulwa S, Kakaire O, Osinde MO, Mbalinda SN, Nabirye RC, et al. Maternal near misses from two referral hospitals in Uganda: a prospective cohort study on incidence, determinants and prognostic factors. BMC Pregnancy Childbirth. 2016;1:10.

5. Mundkur A, Nambiar KPMK, Rai L. Low platelet counts in pregnancy: an alarm signal for abruption! Int J Reprod Contracep Obstet Gynecol. 2018;7(3):1191-5.

6. Parnas M, Sheiner E, Shoham I, Burstein E. Moderate to severe thrombocytopenia during pregnancy. Eur J Obstet Gynecol. 2006;7(4):6.

7. Olayemi A, Akuffo FW. Gestational thrombocytopenia among pregnant Ghanaian women. Pan Afr Med J. 2012;12(34):2-7.

8. Stasi R. How to approach thrombocytopenia. Am Soc Hematol. 2012;2012:191-7.

9. Puri M, Nigam A, Agarwal K. Fetomaternal outcome in pregnancy with severe thrombocytopenia. Eur Rev Med Pharmacol Sci. 2012;16(12):1563-6.

10. Cines DB, Levine LD. Thrombocytopenia in pregnancy. Am Soc Hematol. 2018;130(21):2271-8.

11. Mccrae KR, Bussel JB, Mannucci PM, Remuzzi G, Cines DB. Platelets: an update on diagnosis and management of thrombocytopenic disorders. Am Soc Hematol. 2001;4:34-9.

12. Asrie F, Enawgaw B, Getaneh Z. Prevalence of thrombocytopenia among pregnant women attending antenatal care service at Gondar University Teaching Hospital in 2014, northwest Ethiopia. J Blood Med. 2017;2017(8):61-6.

13. Yazdani S, Bouzari Z, Sedaghat S, Samakoosh MA, Farajnezhad K. Incidence of thrombocytopenia in 
pregnancy and associated factors. J Maz Univ Med Sci. 2012;22(89):59-64.

14. Vishwekar PS, Yadav RK, Gohel CB. Thrombocytopenia during pregnancy and its outcome-a prospective study. J Krishna Inst Med Sci Univ. 2017;6(1):82-9.

15. Wang $\mathrm{X}, \mathrm{Xu} \mathrm{Y}$, Luo W, Feng H, Luo Y, Wang Y, et al. Thrombocytopenia in pregnancy with different diagnoses. Medicine (Baltimore). 2017;96(29):1-5.

16. Yassaee F, Eskandari ZA. Pregnancy outcomes in women with idiopathic thrombocytopenic purpura. Iran J Reprod Med. 2012;10(5):489-92.

17. Borna S, Borna SK. Maternal and neonatal outcomes in pregnant women with immune thrombocytopenic purpura. Arch Iran Med. 2016;9(2):115-8.
18. Jodkowska A, Martynowicz H, Kaczmarek-wdowiak B, Mazur G. Thrombocytopenia in pregnancypathogenesis and diagnostic approach. Postep Hig Med Dosw. 2015;69(15):1215-21.

19. Zutshi NG, Arora RSD. Prevalence of gestational thrombocytopenia and its effect on. Iraq J Haematol. 2019;4:70-3.

20. Elveđi-gašparović V, Beljan P, Gverić-ahmetašević S, Schuster S, Škrablin S. Fetal-maternal complications and their association with gestational thrombocytopenia. Ginekol Pol. 2016;87(6):454-9.

Cite this article as: Ruiru D, Nzabandora E, Ssebuufu R, Byonanuwe S. Immediate maternal complications associated with thrombocytopenia among women delivering at a tertiary hospital in Southwestern Uganda. Int J Reprod Contracept Obstet Gynecol 2021;10:448-51. 